\title{
Participatory Design and Environmental Education in Visitor Centers: A Case Study from Nepal
}

\author{
Ninni Kim Nhi Hoang 1, Mia Edvardsen 2, Martina Keitsch3 \\ INinni Kim Nhi Hoang \\ kimnh@stud.ntnu.no \\ 2Mia Edvardsen \\ miaed@stud.ntnu.no \\ 3Martina Keitsch \\ martina.keitsch@ntnu.no
}

\begin{abstract}
Creating behavior change to mobilize transitions toward sustainability is a significant challenge of our time. To change behavior, people, first of all, have to be informed. Visitor centers, especially in areas of natural beauty and ecological significance, may offer an effective strategy for expanding climate literacy. However, many visitor centers still focus on raising awareness through information dissemination, which is unlikely to lead to behavior change. This paper discusses how environmental education in visitor centers can be enhanced through participatory design approaches in theory and through a design project. Participatory design provides useful methods and tools to capture visitors' diverse needs and backgrounds. This allows to design exhibits that highlight environmental consequences relevant to the visitors' contexts. Overall, acknowledging visitors as participants in an interactive experience setting may contribute to improved lifelong environmental learning and pro-environmental behavior.
\end{abstract}

Keywords: Visitor participation, learning experience, participatory design, environmental education

\section{Introduction}

Creating behavior change to mobilize transitions toward sustainability is a significant challenge of our time. Given that human action is at the center of environmental issues, sustainable development ultimately depends on changing human behavior (Zelenika et al., 2018). To change behavior, people, first of all, have to be informed. Many people experience themselves as disconnected from nature, and do not understand how their actions impact the environment or how environmental issues are affecting their lives. Visitor centers, especially in areas of natural beauty and ecological significance, may offer an effective strategy for expanding climate literacy. Many visitor centers already include environmental education as one of their core goals. However, many still focus on 
raising awareness through information dissemination, which is unlikely to lead to behavior change (Stofer et al., 2019). To simply present the information is not enough, visitors must be stimulated to search for new information, and they have to be encouraged to actively process information (Moscardo \& Pearce, 1986). This paper addresses visitor centers as informal learning institutions for environmental education and explores participatory design as an approach when designing exhibitions for environmental educations. In particular, this paper discusses possible answers to the following question: How can environmental education in visitor centers be enhanced through visitor participation? Using Falk and Dierking's (2000) contextual model of learning, this paper explores the impact of visitor participation in different contexts to enhance the overall learning experience in visitor centers, theoretically in the literature study and practically in a project on service design for a center on environmental education in Nepal. The project was done by two master design students as part of a student exchange program, SAMAJ (www.samaj.online/) from Norway to Nepal in Autumn 2019. The main objective of SAMAJ is to integrate the Sustainable Development Goals (SDG) in society by creating synergies between higher education and the Nepalese/ Norwegian social stakeholders through: a) transdisciplinary education via stakeholder collaboration, b) developing methodologies for academia to collaborate directly with societal stakeholders and c) applying and refining methods such as co-design, contextual case studies and fieldwork within existing communities of practices to enhance dialogue, mutual learning and respect.

Following the introduction, section 2 of this paper presents key concepts of experience and environmental learning in visitor centers and introduces the contextual framework of learning from Falk and Dierking to explore behavior in visitor centers. Section 3 utilizes the framework for exploring visitor participation and design methods and tools to enhance the overall learning experience. The goal of this section is to highlight the possibilities and benefits of visitor participation through an understanding of how learning works and how visitors behave in visitor centers. In section 4 we present the project, designing a concept for an environmental education center in Nepal. Further, we reflect on how to include participation in visitor centers within a reallife setting. Section 5 discusses the value of participation to build up environmental education in visitor centers.

\section{Experience and environmental education in visitor centers}

\subsection{Environmental education and learning}

The term environmental education comprises all aspects of education, communication, and training for sustainable development (UNEP, 2005). According to UNESCO (2014) environmental education, as well as education for sustainable development, aims to prepare citizens with the values and principles of sustainable development, the knowledge of sustainability issues, and the skills and motivation to apply this knowledge to their own actions at local, national, regional and global levels.

Often, environmental education implies formal education in classrooms, although formal education may only reach the younger population, and only 5\% of an average lifetime is spent in classrooms, as pointed out by Falk and Dierking (2010). Thus, non-formal or informal education in visitor centers may be especially needed to expose the older population to environmental education, and 
for the public to keep up with changes in scientific knowledge (Swim et al. 2017). In addition, classroom-based learning does not allow for contact with nature, which Chawla (2006) suggests is a key factor for fostering values of conservation and preservation in kids and adults alike. "Humans do not protect what they do not know and value," as put by Amel $(2017$, p. 1). Visitor centers, with the goal of environmental education, are usually placed in areas of natural beauty and ecological significance, such as national parks, as well as botanical gardens, zoos, and aquariums. Thus, visitor centers represent not only a valuable source of environmental education, but also a good opportunity to relax and enjoy nature.

Various theories have shaped the understanding of learning in visitor centers. In an effort to organize the complexities of learning in free-choice settings from a visitor's perspective, Falk and Dierking (1992) proposed a framework that draws from constructivist, cognitive, as well as sociocultural theories of learning. The contextual model of learning portrays learning as the interactions between personal, sociocultural, and physical contexts over time [Figure 1].

\section{- Personal context}

In the contextual model, the personal context includes motivations and expectations, prior knowledge, experiences and interests, choice, and control (Falk \& Dierking, 2005).

\section{- Sociocultural context}

The sociocultural context accounts for within-group mediation and mediation by others outside the immediate social group. (Falk \& Dierking, 2005).

\section{- Physical context}

The physical context consists of the orientation to the physical space, architecture of the largescale environment, design of the small-scale environment such as exhibits and programs, and subsequent reinforcing events and experiences outside the museum (Falk \& Dierking, 2005).

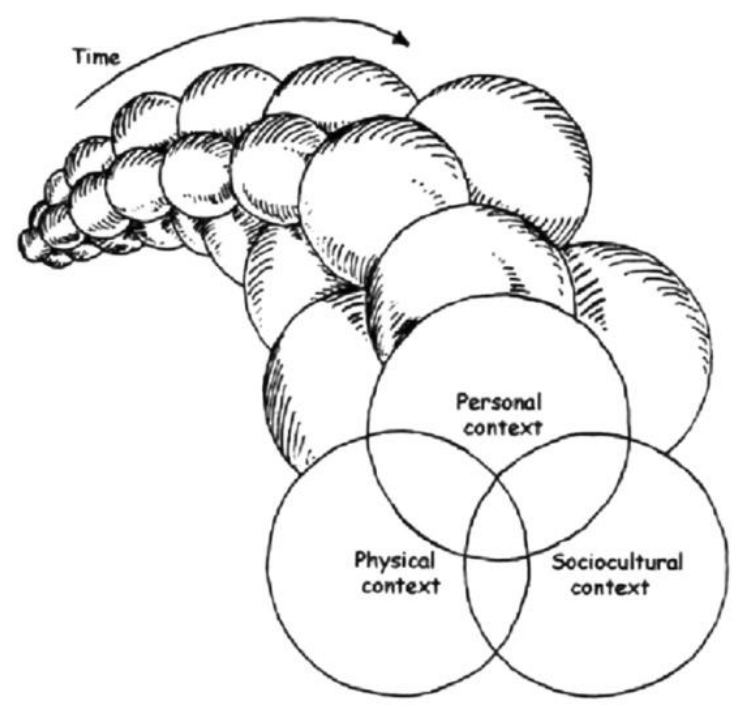

Figure 1. The contextual model of learning. Reprinted from Learning from museums: Visitor experiences and the making of meaning (p. 12), by J. H. Falk \& L. D. Dierking, 2000, Walnut Creek: AltaMira Press. Copyright $\odot 2000$ by AltaMira Press. 
According to Falk and Dierking (1992, p. 67): "Each visitor's experience is different because each brings his or her personal and social context because each is differently affected by the physical." A key understanding that follows from this perspective is that in the end, what individuals learn depends not only upon the content of the exhibitions and programs but equally upon visitors' prior knowledge, experience, beliefs, and interest and what they actually see, do, talk, and think about during the experience (Falk \& Dierking, 2005).

\subsection{Participatory design}

Participatory design means for a designer to organize a design process in a way that users and stakeholders have a part in it. It is widely characterized by user involvement (Spinuzzi, 2005). Participatory design emphasizes the value of direct user participation in the design process. The core methods of participatory design include workshops and design sessions where users are encouraged to think creatively and propose their own ideas. Beyond workshops, standard methods of participatory design include prototyping and testing, where designers prepare prototypes and obtain feedback from users in an iterative manner or where users are encouraged to modify the prototype. Ethnography is often used in conjunction with participatory design to gain a deeper understanding of users (Yamauchi, 2012). With reference to museums and visitor centers, Taxén $(2004,2005)$ states that participatory design is explicitly concerned with enabling visitors to bring their own views and interpretations in the design process to forge more enduring relationships of exchange and cooperation with visitors. Participatory design is only one of the visitor-centered design paradigms. User-centered design and agile design are also variations of a visitor-centered design approach (Sabiescu, 2018).

\section{Visitor participation and experience enhancement}

\subsection{Visitor-centered design process}

Most of the implications of learning, as presented by Falk and Dierking (1992), are widely recognized among other researchers dealing with non-formal learning or informal learning. In particular, the influences of prior knowledge and interests on museum learning have been widely described and documented (Falk \& Dierking, 2005). Burtnyk (2000, p. 281), for example, states that "... knowledge of the visitor is crucial to designing exhibits that will communicate and have the potential to truly educate." Moscardo (1998, p. 154) also argues that if visitor center interpretation is to be improved, it is critical to "better understand what visitors already know, need to know, and want to know." By taking a closer look at how visitors behave, visitor centers can make better matches between visitors' expectations and the visitor centers' objectives. Also, designers can make more informed choices about different kinds of media and experiences visitor centers might offer. Ultimately, all of this can lead to increased visitor satisfaction with meaningful visitor center experiences and effective learning in exhibitions (Chang, 2006).

Participatory design is a design approach specifically intended to help ensure that the results meet visitor's needs. Simon (2010) describes that in co-creative projects, community members work together with institutional staff members from the beginning to define the project's goals and to generate the program or exhibit based on community interests. Taxen (2005) outlines four phases 
to exhibit projects. The first phase is the conceptual phase where ideas for the exhibitions are developed into some sort of description. The second phase is the development phase where the description is implemented. The third phase is the functional phase when the exhibition is on display. The fourth phase is the assessment phase when the exhibition is evaluated. In the conceptual phase, participatory design advocates to include users in co-creation workshops or design sessions. Since redesigning exhibits after they have been put on display is costly, many visitor centers have adopted a prototype-oriented design process where early exhibit versions are tested by a selected group of visitors (Taxen, 2005). In the assessment phase, visitors might be requested to give feedback. A large number of evaluation methods exist, including questionnaire surveys, in-depth interviews, structured and semi-structured interviews, and behavioral observation (Simon, 2010).

Sabiescu (2018) argues that the potential for change in visitor centers depends on the extent to which design approaches are embraced. A small-scale participatory project will not change relations with visitors in the long term. However, enduring participatory practices, such as those described by Simon in The art of relevance (2016) and The participatory museum (2010), will (Sabiescu, 2018). Simon (2010, "Preface: Why participate?", para. 5) defines a participatory institution as "a place where visitors can create, share, and connect with each other around content." According to Simon (2010, "Preface: Why participate?", para. 6), "the goal of participatory techniques is both to meet visitors' expectations for active engagement and to do so in a way that furthers the mission and core values of the institution."

\subsection{Visitor behavior}

According to Falk and Dierking (2005), from the personal context perspective, one should expect new learning to be scaled to the realities of an individual's motivations and expectations. In the case of nature-based visitor centers addressed in this paper, the motivations for visiting are most likely tied to the surrounding areas connected to the visitor centers. Ballantyne, Packer, and Hughes (2008) compared the motivations of different free-choice learning environments and found that visitors rated restoration as more important and learning as less important as motivations for visiting national parks and botanical gardens. Also, enjoyment was rated higher than learning for natural areas such as national parks and botanical gardens as well as aquariums, while learning was rated higher than enjoyment for cultural areas such as museums and art galleries. McLoughlin (1998) suggests that in natural areas, it is the outdoor sensory experience itself that attracts visitors. Thus, many visitors may simply wish to absorb the atmosphere of their surroundings and have little interest in learning about ecosystems (Ballantyne, Packer \& Hughes, 2008).

\subsection{Design implications}

As visitors are not necessarily highly motivated to learn, activities with a strong educational emphasis are unlikely to appeal. Therefore, Ballantyne, Packer, and Hughes (2008) suggest that preparing visitors for a learning experience at the entrance may increase both their receptivity to sustainable messages and the quality of their subsequent environmental learning. They, for example, suggests using provocative signage to prompt their interest in environmental issues or giving suggestions on how to get the most out of their visit (Ballantyne, Packer \& Hughes, 2008). Furthermore, Simon (2010) states that visitors need to see how institutions are relevant and valuable to their own lives, and the easiest way to deliver that is via personalized entry points that 
speak to people's individual needs and interests. Likewise, Rare and The Behavioural Insights Team (2019) suggests framing messaging to personal values, identities, or interests since people are more likely to respond to messages and pay attention to information that is personalized to them and their context. So, the first step to personalizing visitor centers is to take a visitor-centered approach, such as participatory design. By understanding the users or giving the visitors an option to personalize the experience, visitor centers are more readily able to motivate people towards environmental learning. However, how this can be done in the best way seems context- as well as user-depended, and the suggestions from literature would have to be tested in different real-life settings.

\subsection{Visitor participation to enhance socio-cultural experience}

Most visitors go to visitor centers as part of a social group, and according to Falk and Dierking (2005), visitors are strongly influenced by the interactions and collaborations they have with individuals within their own social group. McManus (1991) found different behavior patterns and interactions in museum behavior based on a variety of social contexts. Single visitors tended to read labels in great detail. Couples were characterized by a lack of conversation. Groups with children were very likely to play at interactive exhibits, have longer conversations, and have longer visits. Social groups consisting of only adults appeared to pay the least attention to exhibits. This may be because the main focus in such groups was social interaction within the group, so they paid less attention to displays.

Falk and Dierking (1992) suggest that visitor centers should create some exhibits specifically for all the different groups, keeping in mind that some prefer solitary experience, while some prefer to share experiences even with strangers. The key to maximizing good communication resides once again in providing comprehensible and visitor-centered exhibits. When considering environmental education, participatory learning, as well as social learning is stated by UNESCO (2014) as a particularly useful approach in encouraging learners to ask questions, analyze, think critically, and make decisions in collaboration with others. Thus, leading to the development of skills, proactive citizen behavior, and values on sustainable development. As such, Ballantyne, Packer \& Hughes, 2008 propose that sustainable messages and activities that encourage and enhance social interaction may be effective for all age groups. Simon (2010) also advocates participatory social experiences. She advises designers to have respect individuals' actions and personal space, so they feel confident jumping into a social environment. Thus, multi-person exhibits are built up of individuals' actions and preferences to create a useful and exciting collective result. (Simon, 2010).

\subsection{Visitor participation to enhance the physical experience}

Falk and Dierking (2000) state that since visitor centers are typically free-choice learning settings, the experience is generally voluntary, nonsequential, and highly reactive to what the setting affords. As such, visitor learning is strongly influenced by how successfully visitors can orient within the space. Despite considerable efforts on the part of design teams, it is well documented that many visitors do not view the exhibits in the intended order (Falk \& Dierking, 1992). Visitors choose, sometimes apparently randomly, where they want to focus their attention. What they choose to focus on depends on what they find most visually and intellectually compelling. Again, emphasizing the importance of personal preferences. Prince (1982) (as cited in Moscardo \& Pearce, 1986) carried out a detailed study of visitor learning at two visitor centers in the North Yorkshire 
Moors National Park. The displays were ranked in terms of visitor preference, and it was found that displays containing text only were least preferred, while those containing text and visual elements such as models, photos, and artifacts were most preferred.

\subsection{Design implications}

Despite the efforts to identify exhibits with attracting power and holding power, Falk and Dierking (1992) claim that it has only resulted in exhibits embellished with a multitude of bells and whistles. Visitors may become physically engaged with exhibits featuring high-tech interactive, auditory, and visually displays, but there is little evidence to support intellectual engagement (Falk \& Dierking, 1992). Similarly, Simon (2010), argues that there are ways to achieve meaningful learning with low-tech platforms, many of which are just as effective as and more natural than their high-tech counterparts". Pekarik (2004) (as cited in Chang, 2006) concluded that visitors call for visitor centers that offer a much wider range of presentation approaches with various interpretations and information with multiple texts. Then, visitors will determine what is beneficial and what is not for their learning. Similarly, Brown (2001) (as cited in Ahmad et al., 2015) has claimed that the visitor experience will be enhanced by utilizing alternative media and techniques. McCarthy's 4MAT learning cycle is an approach to ensuring that different learning styles are included. McCarthy (1997) outlined four different learning styles, each with different learning preferences. Type 1 learners are described as highly imaginative students who favor feeling and reflecting. Type 2 learners are described as analytic students who favor reflecting and thinking. Type 3 learners are the common-sense learners who favor thinking and doing. Type 4 learners are defined as the dynamic learners who favor creating and acting. McCarthy (1997, p. 6) suggests that visitor centers are designed in a way that incorporates all learning styles to answer the questions: "Why do I need to know this?" "What exactly is this content or skill?" "How will I use this in my life?" and "If I do use this, what possibilities will it create?"

\section{Service design for a visitor center on environmental education in Nepal}

The project was established in 2019 according to a suggestion by Kushal Gurung, a Nepalese entrepreneur. He is also the CEO of Gandaki Urja Pvt. Ltd., a biogas bottling plant located in Pokhara, Nepal. Within the last two years, the biogas plant has become an educational hub, with many people visiting and requesting information, not only on the technology but also on sustainability in general. The CEO and the Gandaki Urja employees thus aim to establish and design a visitor center to educate visitors about biogas processing, to raise awareness on environmental issues and sustainable development of national significance, as well as encourage community-level and individual-level actions. Currently, the visitors are politicians, government officials, undergraduates, and graduate students in fields related to energy and the environment. 


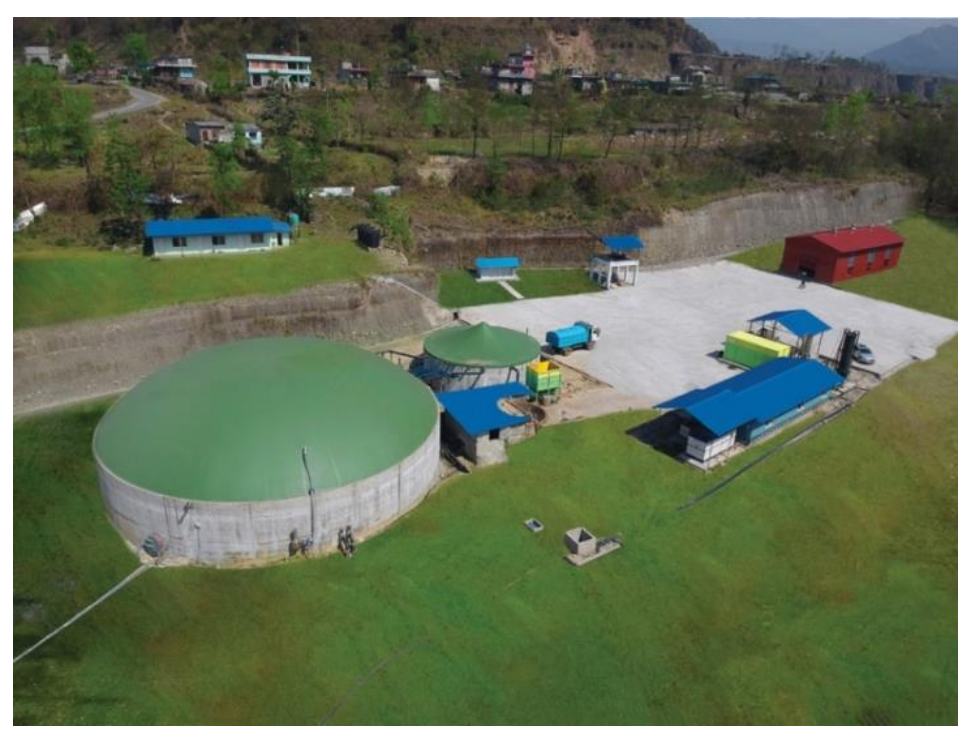

Figure 2. Image of the biogas plant.

The project resulted in a concept, we designed, for an education center with graduate students in fields related to energy and the environment as the target audience. Through the collaboration between NTNU and IOE (www.samaj.online), we got in contact with IOE students, which whom we conducted in-depth interviews to get more background information about the target audience, about existing knowledge on environmental technologies and sustainable practices, previous experiences with museums and visitor centers, as well as general background information such as age, gender, learning preferences, and other interests. Besides, we applied methods such as desk research, onsite observations and stakeholder mapping. Through participatory design methods, such as co-creation sessions, we discussed ideas with visitor representatives who also contributed with their own views and thoughts. They also ensured that environmental messages and interpretation methods were relatable, appropriate, and appealing.

Developing the concept, we had to consider that different visitors would have different interests, emphasizing either the technical, environmental, economic, and social aspects. An engineer might be more interested in going into details of the technological process than an environmentalist. They also had different learning preferences. As such, the concept for the visitor center tried to include a variety of learning styles, such as visual, auditory, reading/ writing, and kinesthetic. Through a variety of interpretation methods, including participatory exhibits, visitors would have the opportunity to be active learners rather than passive observers, ultimately enhancing the learning experience and the potential for behavior change.

We got continuous feedback from Gandaki Urja and our supervisor and had several opportunities to iterate for ourselves. We iterated several times, trying to detail the ideas. The tour of the biogas plant and the four parts of the visitor center are shown below in Figure 3 stayed the same. In the second iteration, illustrated in Figure 4., we expanded the individual visitor journey, and focused on encouraging change in attitude and behavior, asking: "What can I do?" We added interactive exhibits, where visitors could learn about waste sorting, composting, and gardening. 


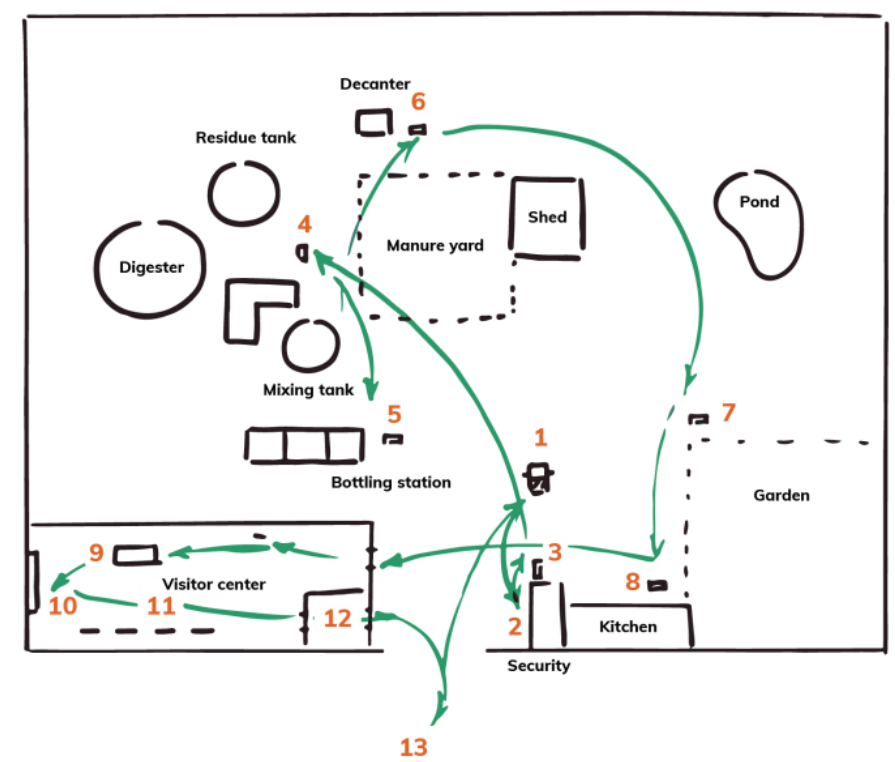

Figure 3. Service journey for the visitor center

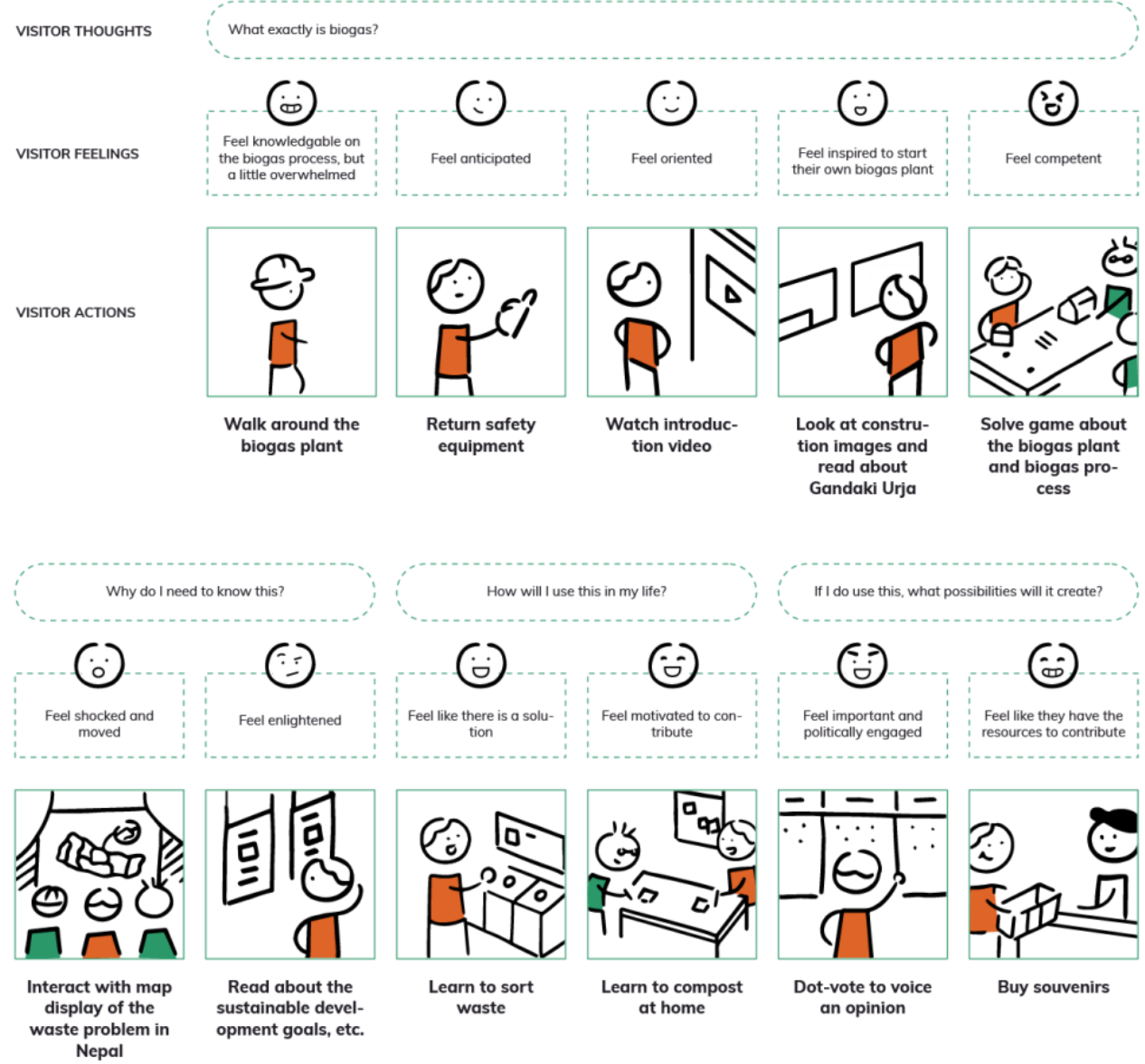

Figure 4. Blueprint of the concept showing which thoughts, feelings, and actions the different exhibits are supposed to evoke, as well as what type of information is learned at each exhibit. For full report and display, please visit: https://www.samaj.online/education-center 
In the third and final iteration, we changed the individual level to encompass not only individuallevel actions, but also community-level actions, by encouraging people to be proactive and politically engaged through social incentives such as suggestion board and dot-vote on political topics related to sustainable development.

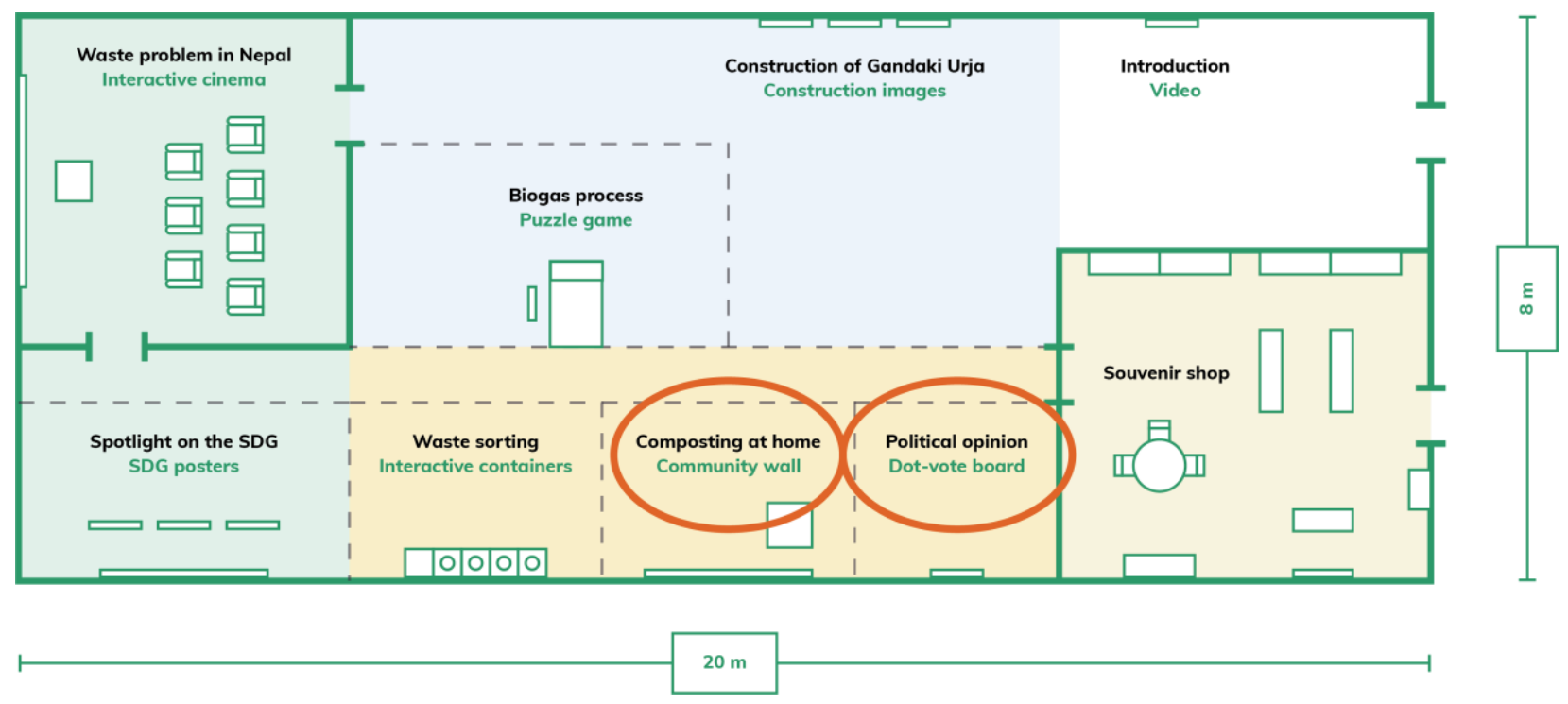

Figure 5. Education center plan

Possibilities and challenges of implementing participatory design in the design process and designing participatory exhibits in visitor centers vary to a certain degree. First, it is important to note that because of personal and socio-cultural contexts although displays, exhibits, and programs in a visitor center are similar, visitors' experiences different. Also, learning in visitor centers is different from learning in any other settings due to the unique nature of the visitor center context (Falk \& Storksdieck, 2005). Designing a visitor center in Nepal is likely to be different than designing in a visitor center in Norway and it seems essential to be sensitive towards contextual personal, social, and cultural conditions.

\section{Conclusion}

Environmental education in visitor centers is highly contextual, affected by personal, social, and physical contexts. Participatory design provides a useful approach to capture visitor's diverse needs and backgrounds. Understanding the visitors makes it possible to design exhibits that highlight environmental consequences that are relevant in the visitor's contexts. Additionally, participatory exhibits, where visitors can interact and are encouraged to create, share, and connect with other visitors, enhanced learning and engagement. The design project in Nepal aimed to create a visitor center for a biogas plant to increase environmental awareness. Through participatory design methods, such as co-creation sessions, visitor representatives were able to contribute with their own ideas. They ensured that the environmental messages and interpretation methods were relatable, appropriate, and appealing. Through participatory exhibits, visitors also get the opportunity to become active learners rather than passive observers. Applying insights from theory 
concepts in a real-life setting allowed to implement participatory and service design methods. Designing user experiences for the biogas exhibition helps visitors to learn in their own ways about possibilities of biogas. Including visitors as participants in an environmental exhibition design seems also to have a positive impact on lifelong environmental learning and pro-environmental

behavior considering their motivation and understanding. Ultimately this enhances the learning experience and the potential for behavior change.

\section{References}

Ahmad, S., Abbas, M. Y., Yusof, W. Z. M. \& Taib, M. Z. M. (2015). Adapting museum visitors as participants benefits their learning experience? Procedia: Social and behavioral science, 168, 156-170. DOI: 10.1016/j.sbspro.2014.10.221

Allen, S. (2007). Exhibit design in science museums: Dealing with a constructivist dilemma. In J. H. Falk, L. D. Dierking, S. Foutz. (Eds.) In principle, in practice: Museums as learning institutions (p. 43-56). Plymouth: AltaMira Press.

Amel, E., Manning, C., Scott, B. \& Koger, S. (2017). Beyond the roots of human inaction: Fostering collective effort toward ecosystem conservation. Science, 356, 275-279. DOI: 10.1126/science.aal1931

Ballantyne, R., Packer, J., and Hughes, K. (2008) Environmental awareness, interests and motives of Botanic Gardens visitors: Implications for interpretive practice. Tourism Management, 29(3), 439-444. DOI: 10.1016/j.tourman.2007.05.006

Burtnyk, K. (2000). Impact of observatory visitor centres on the public's understanding of astronomy. Publications of the Astronomical Society of Australia, 17(3), 275-281. DOI: 10.1071/AS00043

Chang, E. (2006). Interactive experiences and contextual learning in museums. National Art Education Association, 47(2), 170-186. Retrieved from https://www.jstor.org/stable/3497107

Chawla, L. (2006). Learning to love the natural world enough to protect it. Barn, 2, 57-78.

Falk, J. H. \& Dierking, L. D. (1992). The museum experience. Washington, DC: Whalesback Books.

Falk, J. H. \& Dierking, L. D. (2000). Learning from museums: Visitor experiences and the making of meaning. Walnut Creek: AltaMira Press.

Falk, J. H. \& Dierking, L. D. (2013). The museum experience revisited. Walnut Creek, CA: Left Coast Press.

Falk, J. H. \& Dierking, L. D. (2005). Using the contextual model of learning to understand visitor learning from science center exhibition. Science Education, 89(5), 744-778. DOI: $10.1002 /$ sce. 20078

Falk, J. H. \& Storksdieck, M. (2005). Learning science from museums. História Ciências SaúdeManguinhos, 12, 43-117.

Fallon, L. \& Kriwoken, L. K. (2002). Key elements contributing to effective and sustainable visitor centres: An evaluation of the Strahan Visitor Centre, Tasmania, Australia. Gold Coast, Queensland: Cooperative Research Centre for Sustainable Tourism.

Langer, E. J., Blank, A. \& Chanowitz, B. (1978). The mindlessness of ostensibly thoughtful action. Journal of Personality and Social Psychology, 36, 635-642.

Lundgren, L., Stofer, K. A., Dunckel, B. A., Krieger, J., Lange, M. \& James, V. (2019). Panelbased exhibit using participatory design elements may motivate behavior change. Journal of Science Communication, 18(2), A03. DOI: 10.22323/2.18020203 
McCarthy, B. (1997). A tale of four learners: 4MAT's learning styles. How children learn, 54(6), 46-51.

McManus, P. (1991). Visitors: Their expectations and social behavior. In G. Durbin (Ed.) Developing museum exhibitions for lifelong learning (p. 59-62). London: Museums and Galleries Commission.

Moscardo, G. \& Pearce, P. L. (1986). Visitor centres and environmental interpretation: An exploration of the relationships among visitor enjoyment, understanding and mindfulness. Journal of Environmental Psychology, 6, 89-108.

Moscardo, G. (1998). Interpretation and sustainable tourism: functions, examples and principles. Journal of Tourism Studies, 9(1), 2-13.

Ott, A. (2014). Museums, learning centers and education for sustainable development: Practices and possibilities in the Oslo area (Master's thesis). University of Oslo, Norway.

Rare and The Behavioural Insights Team. (2019). Behavior change for nature: A behavioral science toolkit for practitioners. Arlington, VA: Rare.

Sabiescu, A. (2018). A critical reflection on three paradigms in museum experience design. In A. Vermeeren, L. Calvi. \& A. Sabiescu. (Eds.) Museum experience design: Crowds, ecosystems and novel technologies (p. 259-276). Cham: Springer. DOI: 10.1007/978-3$319-58550-5$

Spinuzzi, C. (2005). The methodology of participatory design. Technical Communication, 52(2), 165-174.

Simon, N. (2010). The participatory museum. Retrieved from http://www.participatorymuseum.org/read/

Simon, N. (2016). The art of relevance. Retrieved from http://www.artofrelevance.org/readonline/

Stofer, K. A., Lundgren, L., Dunckel, B. A., James, V., Lange, M. \& Krieger, J. (2019). Public Engagement on Climate and Health in Museums and Participatory Dialogues may Foster Behavior Change. Journal of STEM Outreach, 2, 1-13. DOI: 10.15695/jstem/v2i1.10

Swim, J. K., Geiger, N. Fraser, J. \& Pletcher, N. (2017). Climate change education at naturebased museums. The Museum Journal, 60(1), 101-119. DOI: 10.1111/cura.12187

Taxén, G. (2004). Introducing participatory design in museums. Proceedings of the eighth conference on participatory design: Artful integration: Interweaving media, materials and practices, 1, 204-213. DOI: 10.1145/1011870.1011894

Taxén, G. (2005). Participatory design in museums: Visitor-oriented perspectives on exhibit design (Doctoral dissertation). Royal Institute of Technology, Stockholm, Sweden.

UNEP. (2005). Strategy for environmental education and training: A strategy and action planning for the decade 2005-2014. Retrieved from https://www.unenvironment.org/resources/report/unep-strategy-environmental-educationand-training-strategy-and-action-planning

UNESCO. (2014). Shaping the future we want: UN decade of education for sustainable development. Retrieved from https://unesdoc.unesco.org/ark:/48223/pf0000230171

Yamauchi, Y. (2012). Participatory design. In T. Ishida (Eds.) Field informatics (p. 123-138). Berlin: Springer.

Zelenika, I., Moreau, T., Lane, O., \& Zhao, J. (2018). Sustainability education in a botanical garden promotes environmental knowledge, attitudes and willingness to act.

Environmental Education Research, 24(11), 1581-1596. DOI:

10.1080/13504622.2018.1492705 